\title{
The Open Door: Parent Oriented Programming
}

\author{
Peggy Byrd and Ruth Roland
}

\section{Peggy Byrd}

I recently entered the full-time job market. I applied for a specific position and progressed through all the interviews. After the last round, I was feeling especially proud of myself, and I met a member of the faculty in the hall. She said, "I just wanted to tell you that I told that committee that we wanted someone who didn't know too much, and Peggy Byrd was exactly what we wanted."

The older I get and the longer I stay around this world, the more aware I am of my role as someone "who doesn't know too much," so every once in a while the Fates seem to take over guiding events through an experience designed purely for the enriching of Peggy Byrd. One such event happened last spring when I had a cup of tea with Ruth Roland.

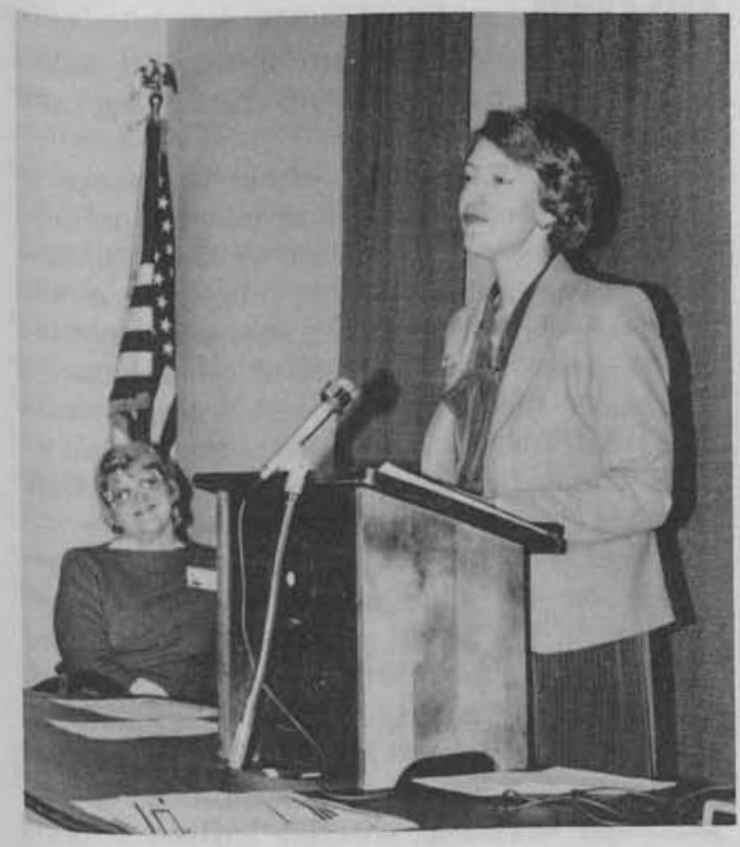

Peggy Byrd and Ruth Roland are independent consultants. Their speech was co-sponsored by the Children's Services Section and the North Carolina Assocation of School Librarians. We thank Judie Davie for providing the journal with this transcript of their talk.
In the course of our tea party, we talked about ourselves as mothers with the "responsibility for hearth and home," and we talked about ourselves as "librarians without portfolio" but with a very real commitment to the profession. We had tried the volunteering routine in a variety of school settings, and we were weary of health room duty and typing circulation cards; so we decided to look at what was going on in our community. We looked at our colleagues in the public schools and in public libraries. We saw how much the realities of everyday life were affecting what we knew to be their hopes and dreams in librarianship. Unbeknownst to the other, both Ruth and I were identifying an area in which we could offer active service to the community and use our skills in librarianship. Lacking media centers of our own, we decided that we would pool our resources and identify one service area, actively recruiting an audience for that one service. What we chose to offer was children's literature and reading guidance to parents and educators in our local community. The result of that morning's tea party was the Open Door.

We were very aware of many people in the community saying, "Parents must get involved in their children's reading life," but no one was really telling parents how to do that. So one thing that we felt a very real commitment to was to offer a structure to parents who wanted to get involved but didn't know quite how to get started. We actively pursue that one population, broadening parental understandings of children's literature and sharing ways they can use reading at home in a comfortable environment in a carefully planned program of selection. In other words, we do what all of us want to do when we go into librarianship: we are trying to get kids and books together, using the adults in their lives as our vehicle.

We thought we would share the organizational pattern that we are evolving, tell you what elements in our community we tapped and of the responses that we have gotten, because we have hit the jackpot! We have spoken to a need. And we have gotten the response we hoped we would. 
Our brochure is very modest, and we sent two hundred of them-to day care centers, to public libraries, to public schools, to PTA chairmen, to some service groups. We have gotten a good percentage of responses from this very small number of mailings.

We've gotten inquiries from groups that wanted staff development. Teachers needed crash courses in children's literature, four to six hour workshops, mostly updating what they knew of children's literature in their teacher education programs $x$ number of years before. We've had day care inquiries, agencies who want to offer parent programs to stimulate reading in the home by giving parents guidelines in choosing books.

PTAs wanted very short programs on the selection procedure, usually in concert with book fairs. We've had inquiries from book dealers who wanted to know if we could plan workshops in concert with book fairs that they were sponsoring. One very interesting group that inquired was a teacher education program for paraprofessionals and non-college graduates who were going into their teaching program who had had no experience in children's literature. They need a fullblown course in children's literature. Finally, we have tapped a specialty preschool in our area that specializes in the arts for three-, four-, and five-year olds, and though they had used literature heavily in their program for the children, they really did not anticipate parental interest in using literature at home. This school has been very interested in the package that we are talking about with their parent groups.

Those were the responses we got from the brochure, and now we are getting that very nice second wave of communication through the grapevine, which has served us very well. The best inquiry we've had was a university in Texas wanting to know if we'd do a continuing education program for parents over several weeks next summer.

Churches are contacting us for family night supper series, which is a marvelous way to get parents and grandparents into our workshops. We are now able to say, quite literally, we have had agencies from Murphy to Manteo contact us, so we've gotten statewide coverage. And we thought we were going to have a nice quiet little cottage industry!

We must say now-and repeat it often - that we are serving as your advance men; we are your publicity agents, because what we're doing is reminding parents of the wealth of community resources that are available to them. We're not your competition; we're your sales representatives. When we do a workshop in a community, we will draw materials from the public library collection, because it's a very nice bonus to be able to say, “The materials that are 'starred' on your bibliography are available at the South Succotash Public Library." We supplement with Open Door purchases only to the extent that we need to provide breadth in the topics we are presenting.

So the program of the Open Door seems to be communicating with a population that has both broad-based needs and very specific topical needs. Parents want very basic instruction in the selection of children's materials-how you go about doing it-and a lot of hands-on experience. You know and we know that when an individal sees a book and likes it on the spot, she or he will use it in whatever context it is taken. We provide a lot of hands-on experience, a lot of on-the-spot evaluation, and discussions; and it seems to click.

Friends in the profession want to know how our workshops are put together, what we do in these workshops, and where we're going now that this thing has really begun to snowball, what sort of patterns we are moving into with this series. The one person who gives all these inquiries a cogency and a structure and a sense of order is my friend Ruth Roland.

\section{Ruth Roland}

In putting a workshop together, we follow three basic steps: planning, presenting, and evaluating.

We individualize each of our workshops to meet the specific needs and interests of that sponsoring agency. Therefore, we like to involve the sponsors from the very beginning in the planning process. We usually submit a suggested list of topics. The members of the sponsoring committee then choose the topics they want presented. They are not limited to this list, but we have found the list helpful in guiding their selection choices.

Together with the planning committee, we decide on the different components of the workshops: the length, the group size, and the topics. The planning process not only identifies the specific topics but also gives us a chance to get a feel for the group that we'll be working with, so that we can adapt our presentation for that particular workshop. We have enjoyed working with the different planning groups, and we have found what we expected to find: most groups are interested in a basic course in children's litera ture presented in two-hour time blocks. 
The presentation also depends on the needs and the interests of the specific sponsoring agency, and hopefully after the planning process, we have a fair picture of what that group expects. When we started out, we naively thought we could work up a few basic workshop outlines and bibliographies and repeat them at each workshop. We found that this has not been the case. We have truly individualized each of our workshops to meet the needs of the sponsoring group.

Of course, there are certain things that should be a part of every workshop. Two of our primary goals are: (1) to provide the parents with criteria for selecting literature; and (2) to give them the hands-on experience with the materials. Parents should be given the criteria for selecting books and nonprint materials in a supportive and nonthreatening way. Our workshops are informal, and discussion and questions are encouraged. After all, we're trying to get parents to use libraries and librarians, and we want them to feel comfortable with both.

We present the selection criteria in several ways. For example, a local bookstore is sponsoring Tuesday morning kaffee klatsches. We get together with the bookshop owners and select one topic a month to present to the parents that attend. In each of these sessions, we hand out a very short bibliography. Sometimes we list the criteria for this type of literature on the bibliography. Sometimes we go over the criteria as we are presenting the materials. When we are addressing a large group, we have a slide show that we've developed to present the selection criteria. Most of our groups have had no more than twenty-five participants. We divide into two groups when it's time to actually look at the materials. This gives everyone a chance to handle and examine the materials. This hands-on part of the workshop is my favorite part. I love to hear the "oohs" and the "aahs" and the "Oh, I remember this one," or "I wish they had books like this when I was a child," to which I promptly respond, "There's no reason you can't enjoy them now that you're an adult."

The parents in our workshops have been very eager to give their opinions on the illustrations found in the picture books. They may not feel qualified as literary critics, but almost everyone has an opinion on the art work of the book.

Our hands-on role becomes more challenging when we are working with a larger group. If we cannot break down into small groups, we try to allow plenty of time at the end of the presentation for browsing and for conversation. We'll soon be doing a short PTA program as a lead-in for a school's book fair. When we go over our selection criteria, we will suggest some resources and books that are good for family read-alouds. Then we will be available, along with the media specialist, at the book fair to answer questions and aid in selection.

A nice side benefit to the hands-on part of the workshop is the communication that is set up between the parents and between the parents and us. We feel that this further helps to reinforce the idea of librarians as being service-oriented. We make it very clear that we are librarians, and that librarians can be part of the team to bring these parents the information that they want and need.

We have gotten very enthusiastic responses from parents when we show them selection tools. We have found that parents want to know about Children's Catalog, Elementary School Library Collection, A to Zoo, and The Bookfinder. They also want to know how to use them. Recently we were with a group of ministers who wanted to know how they could find books on family relations. They were especially interested in books dealing with adoption, divorce, and death for intermediate age children. We took about five minutes, showed them the Elementary School Library Collection and how to use the subject index. In a short time, they had a wealth of material in many formats to meet their needs. We showed them ESLC not only because of its usefulness, but also because it was available in their local public library. Whenever possible, we try to make the parents aware of the resources that are available in their local area.

The final element of our workshop is the evaluation process. We wanted the evaluation to be informal but also helpful to us for future planning. Most of the evaluation is gathered orally from the parents during the course of the workshop. We also have a short evaluation form which we ask them to fill out. They can give some general reactions to the workshops and indicate topics of further interest for future workshops.

The programs of the Open Door have continued to expand as we become aware of new opportunities and areas of service. For example, we have just finished putting together a workshop dealing with the building of self-esteem and literature to support that development. We will be presenting the literature portion of the workshop, and a marriage and family therapist in our community will be presenting techniques for building self-esteem. We think that librarians have a unique opportunity to pull together 
experts from many fields and offer this expertise to parents' groups. It has been our experience so far that professionals, not only in the library field but in other areas, have been very interested in what we are doing and very supportive of our efforts.

We had decided, in our first year, to concentrate on materials for children from birth through grade six. Because of the interest that we have received, we are already gathering a bank of names of people that deal with other areas, such as the adolescent experience, storytelling, and values clarification.

\section{Peggy Byrd}

Several significant things are increasingly apparent to us the more we do these workshops.

First: Given a satisfactory time slot, parents will come to hear about children's literature. The interest runs extremely high. You will be very surprised and delighted if you make a similar effort in your own local setting at how much interest is there. The secret is to identify the time slot that people can use. We have had good luck with the weekends, evenings, and with the noonhour sack lunch idea.

Second: Given a satisfactory time slot and location, fathers will come to a session on children's literature, and for me, that is the nicest of our "discoveries." Tve done this type of workshop in local churches using the morning Sunday School time and the Wednesday evening family nights, and in each one of these series, I've had equal numbers of moms and dads. Now we find that churches are calling us because they know that we will do things in those two atypical time periods.

Third: Parents will come if they are part of the planning process. We insist that the parental group be included in this initial planning process to set the tone for mutual communication and to put the stamp of "local concerns being met" on the workshop.

Fourth: Parents are discovering and rediscovering that reading at home with their children (even as they move into teen years) is one of the nicest bonds to reestablish within the family. My children still think of the state of Colorado as the place where we camped and read Pooh and Ram ona and froze to death.

I'm reminded of one of my favorite movies, which is Miracle on 34th Street, in which Kris Kringle is hired by Macy's to serve as the holiday Santa Claus, and he says to the parents who are frantic with shopping, "Why are you buying this here? Go across the street to Gimbel's and save $\$ 10$."

Well, we are in that same posture, I think. We are saying, "We'll get you started, but then go across the street to the public library, because that's where your treasure trove of materials is going to be, or go to your school media center for a splendid nucleus." We send them to you better able to articulate their needs and with a foundation in what to look for in children's books.

The last big discovery in doing parent and educator workshops is in a paraphrasing of John Greenleaf Whittier: "The finest words of tongue or pen are simply these: let's do it again."

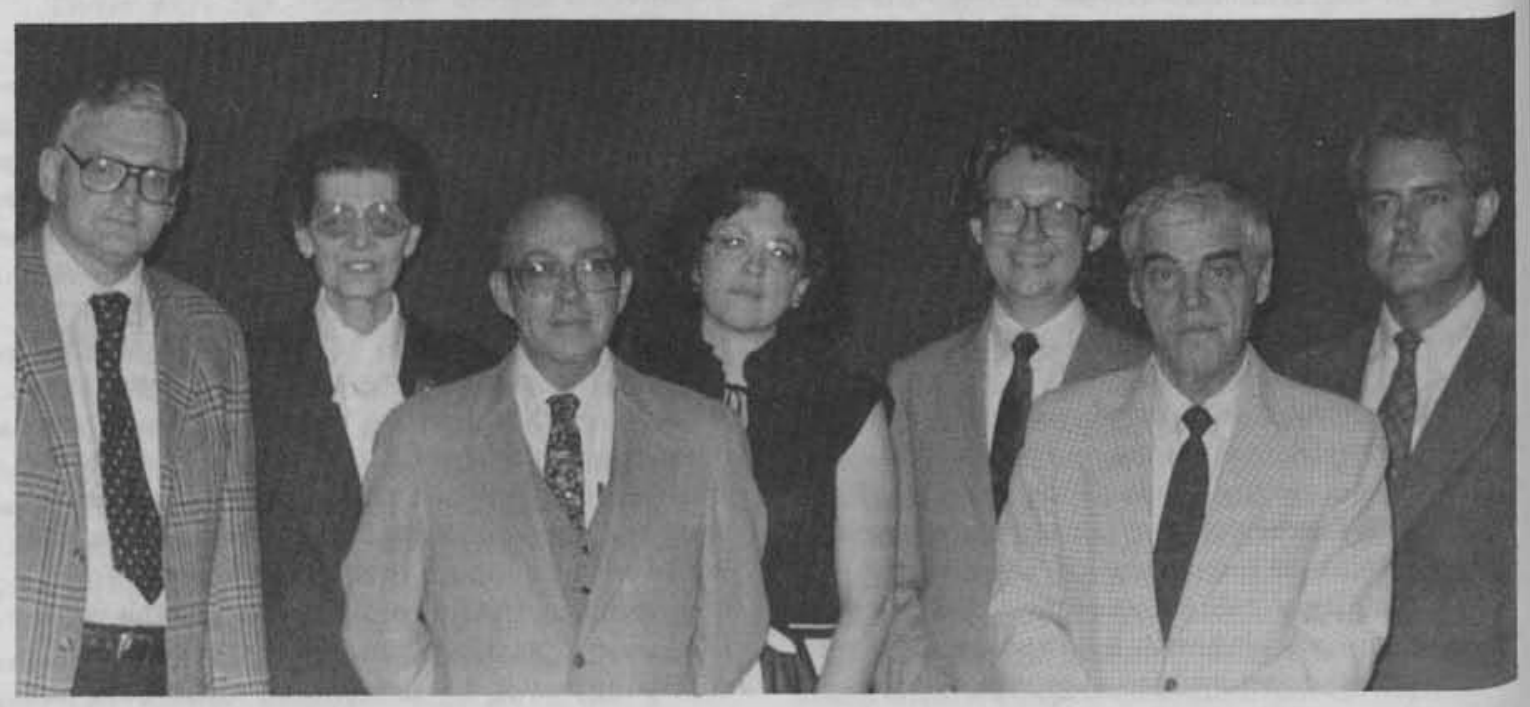

NCLA Conference Committee (1-r): William Kirwan, Mertys Bell, Arial Stephens, Sharon Crowe, Robert Burgin, Larry Roland, Leland Park. (Photo by Frank Sparger.) 